\title{
El legado chino detrás de un apellido castizo
}

Recibido: 19/02/2020

Aprobado: 20/05/2020

Publicado: 25/08/2020
Candy (Li) Cortez Prudencio Universidad Nacional Mayor de San Marcos $<$ slip.2806@gmail.com>

\section{RESUMEN}

La autora mediante el uso de la memoria familiar y revisión de archivos parroquiales reconstruye la historia de dos de sus ancestros chinos que se asentaron en fines del siglo XIX en el distrito de San Luis de Cañete, Lima, Perú. Relata como el cambio de nombre de sus ancestros realizado mediante el bautismo cristiano impacta en su familia y en su propia vida.

Palabras clave: Migración china, identidad personal, descendientes de chinos, adopción de nombres castizos, Cañete.

\section{The chinese legacy hidden by a local last name}

\section{ABSTRACT}

The author by using the family memory and review of parish archives, reconstructs the story of two of her Chinese ancestors who settled in the late 19th century in the San Luis de Cañete district, Lima, Peru. She relates how the change of name of her ancestors carried out through Christian baptism impacts to her family and her own life.

KeYwords: Chinese migration, personal identity, chinese descendants, adoption of local names, Cañete. 


\section{Introducción}

1 presente es un testimonio expuesto en el — evento "Testimonios de tusanes y nikkeis sanmarquinos" realizado en la Facultad de Ciencias Sociales de la Universidad Nacional Mayor de San Marcos en octubre del 2019, a propósito de los 170 años de inmigración china y 120 de inmigración japonesa al Perú. En este texto, narro brevemente la historia de mis ancestros chinos asentados en San Luis de Cańete, abordo el proceso de cambio de nombre que sufrieron mi bisabuelo y tatarabuelo, asimismo, expongo como este cambio afectó a mi familia. También comento algunas conductas de evidente influencia oriental que se mantienen en mi familia y, finalmente, adjunto un pequeño relato que escribí el año pasado acerca de mi bisabuelo y su vida en Cañete.

\section{El origen chino de la familia Cortez}

La identidad de mi familia deriva de la confluencia de los diversos grupos étnicos que llegaron a la provincia de Cañete.

Soy cañetana y tusán de cuarta generación ${ }^{1}$, bisnieta de un inmigrante chino apellidado Li y, por otra línea familiar, tataranieta también de un inmigrante chino, ambos asentados durante fines del siglo XIX en el distrito de San Luis de Cañete.

Cañete es una de las provincias del departamento de Lima, está compuesta por dieciséis distritos. Lleva el nombre de "Cañete", pues, su fundador, el quinto virrey del Perú, Andrés Hurtado de Mendoza y Cabrera, poseía el título nobiliario de origen español correspondiente al Marquesado de Cañete.

El distrito históricamente más importante de la provincia fue San Luis; debido a la gran actividad agrícola que lo caracterizó, socialmente convergieron en distintos o a veces en los mismos períodos históricos: grupos andinos, afros, chinos y japoneses.

Mi bisabuelo se estableció allí aproximadamente en el año 1890 y en un inicio trabajó en la hacienda Arona, luego, según cuenta la historia familiar, debido a su habilidad con los números tuvo la opor-

1 En Perú se utiliza el término tusán para hacer referencia a los descendientes de chinos independientemente de su generación. tunidad de laborar en la contabilidad de la British Sugar Company, usufructuaria de la hacienda Santa Bárbara, en San Luis de Cañete. Posteriormente, incursionó en al ámbito comercial; sin embargo, no conozco más detalles de esa faceta.

Él fue bautizado en la viceparroquia del distrito de San Luis, su padrino se llamaba José Dionicio Cortez. El párroco inscribió a mi bisabuelo con ese mismo nombre en el libro parroquial de bautismos, y es así como desde entonces mi bisabuelo utilizó en la sociedad peruana ese nombre.

Por otro lado, mi bisabuela Aquilina Perez era tusán, hija del matrimonio entre un inmigrante chino y una peruana. Su padre también se bautizó en la viceparroquia del distrito de San Luis, su padrino de bautismo fue el Dr. Manuel Perez, un vecino del pueblo. El párroco registró a mi tatarabuelo como José Perez, en esta ocasión no copió el nombre exacto del padrino, sino solo cambió el nombre de pila. Mi tatarabuelo usó este nombre de igual forma que mi bisabuelo y cuando mi bisabuela Aquilina fue bautizada, la registraron con el apellido castizo Perez.

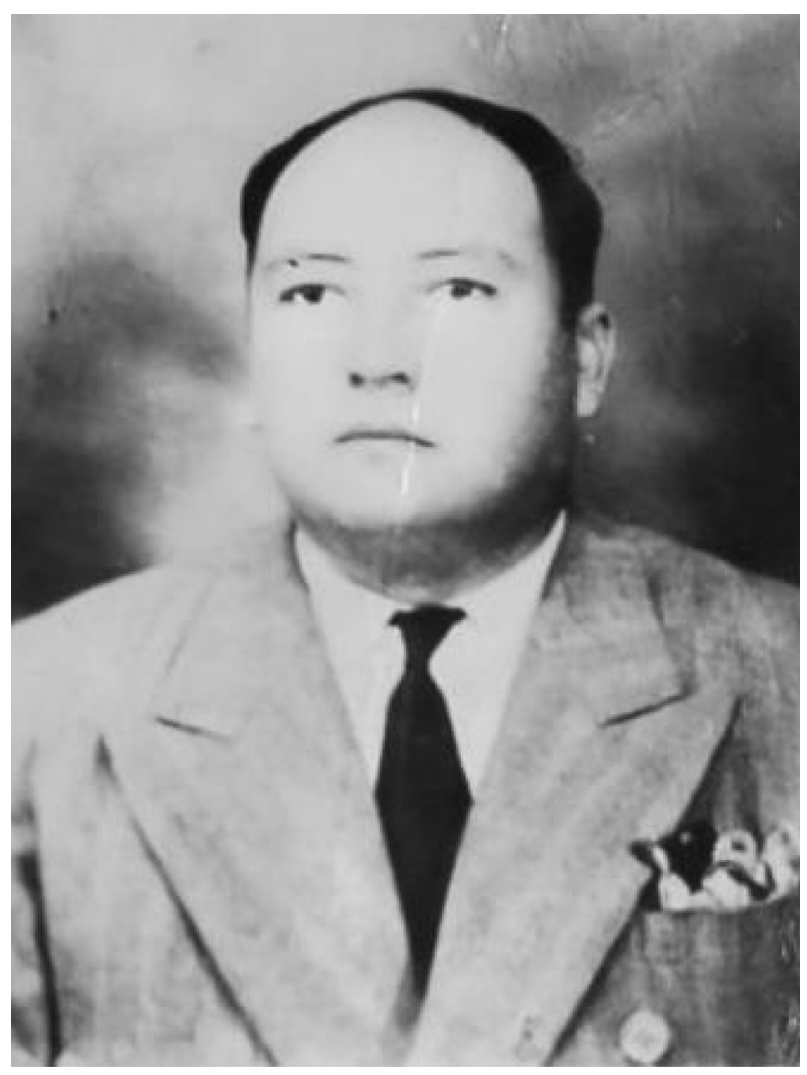

Mi abuelo, Manuel Cortez Perez. 
Mis bisabuelos vivieron en la hacienda Casa Blanca, ubicada también en San Luis de Cañete, donde nacieron mi abuelo y sus tres hermanos.

\section{De Li a Cortez: la variación de apellido}

Como ya mencioné, mis ancestros chinos fueron inscritos con nombres castizos, a través de la práctica del sacramento del bautismo cristiano. Y estos apellidos fueron heredados a las siguientes generaciones.

Todo esto ha sido la razón por la que en mi se marcó el interés incalculable de conocer más sobre el origen chino de mi familia, saber la razón por la que en mi familia se decía y yo escuchaba, que "el apellido Cortez no era nuestro verdadero apellido", que "era un apellido prestado", que "el bisabuelo se cambió de apellido para protegernos y evitar la discriminación de la época" y otra serie de frases con las que se trataba de explicar el origen del apellido Cortez.

El proceso de adopción de nombres castizos por parte de los inmigrantes chinos se dio durante el siglo XIX e inicios del siglo XX. En los inicios de la inmigración, los chinos eran conducidos a las capillas de las haciendas o a las iglesias del pueblo para recibir el sacramento cristiano del bautismo, en la partida bautismal constaba la administración de este sacramento sobre un individuo. Durante el siglo XIX esta tenía el mismo valor legal que una partida de nacimiento de la actualidad: acreditaba relaciones filiales, edad, origen, entre otros. Era un documento que otorgaba derechos a sus titulares.

Los sacerdotes administraban el bautismo y se encargaban de expedir y consignar los datos que creían convenientes dentro de las partidas bautismales, a veces utilizaban formatos pre-establecidos, y en otros redactaban a mano la totalidad de la partida.

En el Archivo Parroquial de la Prelatura de Yauyos que abarca también a la provincia de Cañete, ubicado en el distrito de San Vicente de la misma provincia, se resguardan los libros bautismales del siglo XIX y contiene gran variedad de partidas bautismales donde se observa la permanente adopción y/o imposición de apellidos castizos a los inmigrantes chinos.

Las partidas tienen diversas particularidades, en algunas podemos observar que se consignan términos como "asiático", "chino", "súbdito del Celeste
Imperio" para referirse al inmigrante chino; y respecto a la "raza" se utilizan términos como "amarilla" o "indígena", y en cuanto a los orígenes se señala que son naturales de "Cantón", "China", "Imperio chino", "Pekín”, entre otras. La mayoría de los inmigrantes chinos son adultos y sobrepasan los treinta ańos y por supuesto, son varones. Por lo general, se les registra con el mismo apellido del padrino, y hasta con el mismo nombre de pila, en pocos casos asume el apellido de la madrina de bautismo. En algunas partidas, se indican hasta el nombre del padre y la madre china, categorizándoseles como "infieles" de la Iglesia Católica.

Asimismo, puede verificarse que muchos chinos tienen como fecha de bautismo el mismo día de su matrimonio, por lo que se infiere que accedieron a recibir el bautismo cristiano para poder contraer matrimonio.

A los hijos fruto de un matrimonio se les acuñaba el término de "hijos legítimos", mientras que a los hijos que no eran fruto de un enlace matrimonial religioso se les denominaban "hijos naturales" y a los que eran fruto de una relación adúltera "hijos ilegítimos". Este trato representaba un estigma moral que recaía sobre la persona, además tenía como resultado una abismal diferencia de derechos entre los hijos que ostentaban categorías diferentes.

Asimismo, en el siglo XIX solo los católicos tenían acceso a la sepultura en los cementerios, por lo que los chinos se bautizaron también para poder acceder a una sepultura digna y decorosa como forma de resistencia para mantener sus prácticas culturales en torno a la muerte (Carrasco Atachao 2009: 218).

Como se ha podido apreciar, los chinos tuvieron razones de sobra para ingresar tácticamente a la Iglesia Católica y de esta manera insertarse en la sociedad peruana y poder resistir las condiciones adversas que afrontaban, un ambiente muchas veces hostil donde fueron maltratados y discriminados por todos los sectores sociales que tildaban al chino como el culpable de cualquier mal que tuviera el país, los ridiculizaban por su físico, cultura, idioma, condición social, entre otros. Este proceso concluyó cuando los chinos se sintieron más fuertes en la sociedad receptora (Rodríguez Pastor 2000: 366) 


\section{Identidad vulnerada}

Antes de las visitas al archivo pensaba que el caso de mi bisabuelo era excepcional, no conocía ni sospechaba que este había sido un proceso masivo que no solo se había dado en Perú sino en todos los países hispanoamericanos donde hubo inmigración china durante el siglo XIX. En este proceso cada chino de alguna forma perdía algo de sí mismos, de su cultura, de autoconcepción como individuo perteneciente a un grupo social.

Por tanto, en la actualidad hay muchos descendientes de chinos que aún usan el apellido adoptado por su ancestro, sea como apellido paterno o materno. En algunos casos la variación de apellido no indica que necesariamente se haya diluido todo el espectro cultural chino en estos descendientes; sin embargo, sí puede ser un factor para que ello se intensificara.

Las implicancias culturales que derivan del cambio del verdadero apellido de una persona son diversas. En las familias que descienden de un inmigrante chino que adoptó un apellido castizo se conoce el origen chino familiar, sea por rasgos físicos de los familiares, costumbres, relatos de los familiares mayores, e incluso se conoce el apellido original, sea por poseer un documento donde conste ello o por la tradición oral familiar.

El apellido representa a una familia, a los ancestros, a la historia familiar de la persona, de dónde viene, con quiénes tiene parentesco. Gran parte de la identidad de la persona tiene origen en el apellido que designa al grupo al que pertenece.

Como he mencionado, la inquietud por conocer más de mis raíces chinas nació principalmente debido al cambio de apellido de mi bisabuelo paterno. Crecí al tanto de que usaba un apellido que no correspondía originalmente a mi ancestro, un apellido que alguien "nos prestó", en realidad, era un tema que regularmente se conversaba en reuniones familiares y que desde que tengo memoria se comentó en el hogar. Saber ello desde muy pequeña produjo que no sintiera el apellido paterno parte de mí, ni de mi historia.

La recuperación de la identidad arrebatada directa o indirectamente a mi bisabuelo es mi lucha en la actualidad. El apellido castizo que ahora se encuentra consignado en mi documento de identidad es consecuencia de las difíciles condiciones que tuvo que resistir mi bisabuelo y demás inmigrantes, quienes se vieron, de alguna forma, obligados a desligarse de su

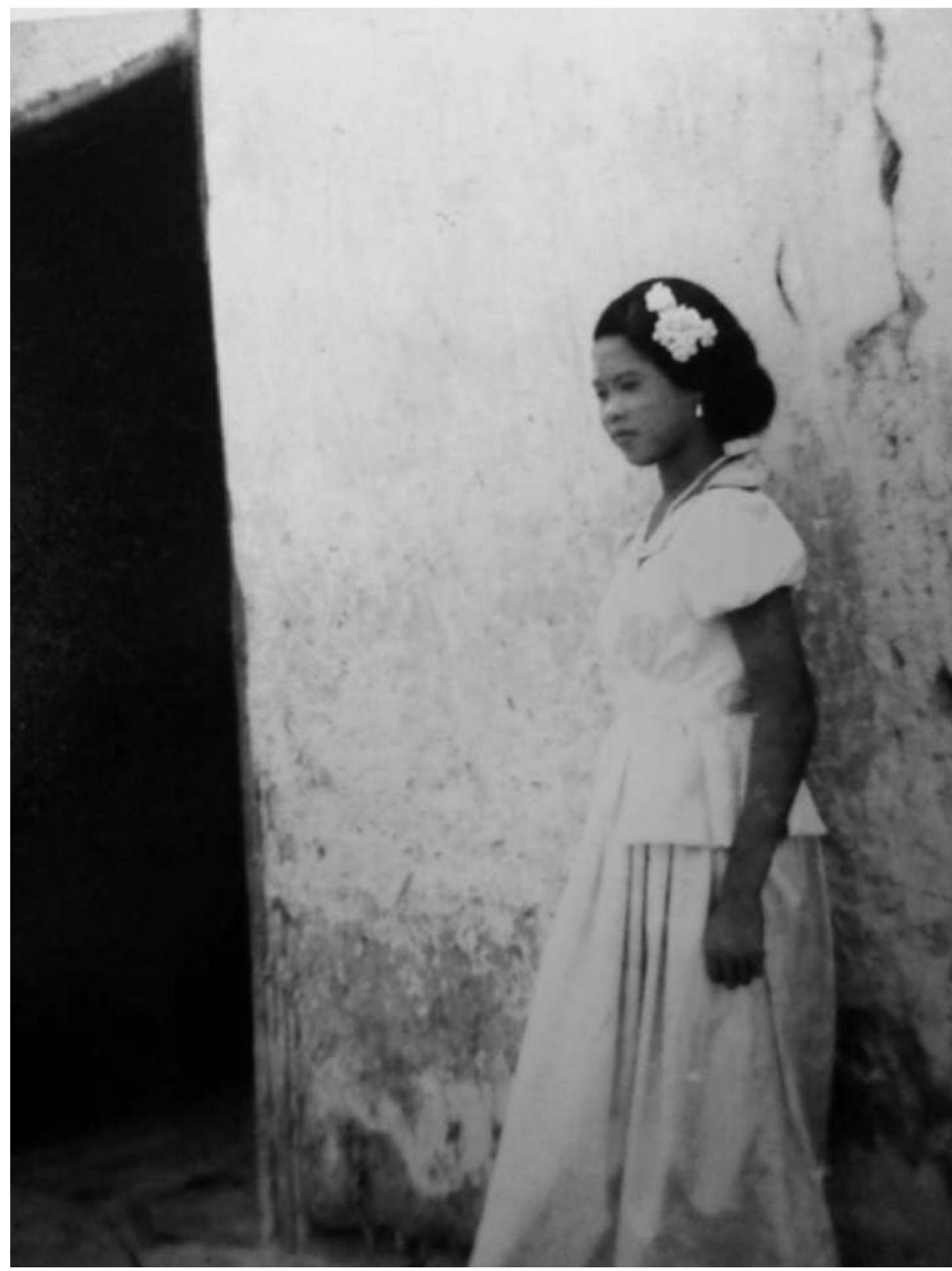

Mi tía Teresa Cortez en San Luis de Cañete, Lima, Perú.

identidad para resistir a la sociedad indolente y hostil que los recibía.

Seguir usando el apellido del padrino de bautismo de mi bisabuelo significa, validar ese período de la historia peruana, validar el maltrato y discriminación al que se vio expuesto y darle la espalda al legado que dejó él a mi familia.

Por tanto, recuperar el apellido de mi bisabuelo sería sinónimo de reivindicar su historia, sus orígenes, reivindicar a su padre, a la familia dejada en China, al llanto de la madre al verlo partir, su largo viaje por el mar, al sudor que regó en la tierra del valle cañetano, a su valentía al enfrentarse a esta sociedad sin siquiera conocer el idioma; y otorgar honor a su memoria, sería casi como decirle que su lucha en esta tierra tan extraña y ajena valió la pena. 


\section{Anécdotas familiares y costumbres asumidas}

Mi abuelo conservó costumbres chinas heredadas de sus padres, comía siempre con "fai chi" intentó enseñarle a mi padre a usarlos, pero él no se interesó mucho en aprender, acudía con regularidad al Barrio Chino donde visitaba con frecuencia a sus paisanos ${ }^{2}$, y dónde adquiría remedios chinos para sus dolencias. Cocinaba bastante, lo hacía para sus hijos, usaba mucha verdura en los platos que realizaba. Hacía platos mezclando cualquier tipo de verdura que tenía al alcance. Le iba bien en los negocios, era contratista de construcción, realizó bastantes obras inclusive era contratado por sus paisanos para construir en el Barrio Chino.

Inculcó en sus hijos valores chinos como el culto a los ancestros, el respeto a los mayores, el trabajo constante y perseverante, la consideración al otro; asimismo, celebraba fiestas tradicionales como el año nuevo chino.

Además de costumbres tradicionales, en mi familia puede observarse ciertas actitudes o conductas que son ligadas al mundo chino, por ejemplo, en Perú, como en otros países, las mujeres han sido quienes se han encargado de cocinar en la gran mayoría de hogares mientras que para los hombres era una actividad que hasta hace algunos años era impensable realizar. Los chinos que vinieron a Perú no veían en la cocina una actividad que mellara su estatus varonil como sí lo piensan muchos varones peruanos, al contrario, ellos sabían cocinar, y lo hicieron en sus galpones, al mediodía en los campos de las haciendas y hasta algunos, cuando cumplían sus contratas, laboraban como cocineros. Obviamente es conocido como muchos de ellos emprendieron negocios en base a la comida, como resultado tenemos a los famosos "chifas" que tienen un valor incalculable en la gastronomía peruana.

Todo esto conllevó a que en muchos de los hogares sinoperuanos sea el varón quién fuera el encargado de la cocina y no la mujer, en los hogares de sus descendientes se puede ver reflejado este aspecto.

A diferencia de varios hogares peruanos, dentro de mi hogar familiar fue mi padre quien estuvo en la mayoría de las veces abocado al trabajo culinario.

2 Comúnmente los chinos asentados en Perú llaman a sus compatriotas o en ocasiones a sus descendientes más cercanos con el término "paisano".
Este lo aprendió así de su padre quién también se encargó de cocinar para su familia, en particular platos con evidente influencia oriental: saltados y el uso de mucha verdura. Él nos preparaba el desayuno, el almuerzo y la cena durante casi toda nuestra vida. Cocinaba siempre contento, no tenía quejas sobre eso, algunos familiares varones lo molestaban por estar "relegado" en la cocina, hecho que jamás se veía en cualquier otro hogar de vecinos o familiares sin ancestros orientales que tenía cerca. Ahora que mi vida se desarrolla en Lima siempre extraño los guisos orientales que solo mi papá sabe preparar.

Asimismo, en la estación de verano e incluso en el invierno se suelen tomar bebidas heladas, acompañando a las comidas o en cualquier instante del día. En la tradición china no se consumen bebidas heladas, solo calientes o tibias, esto tiene resonancia en la medicina china tradicional.

En nuestro caso el tomar bebidas heladas es un acto vetado. Mi papá solo bebe agua caliente, y eso se impregnó en mí, pues es prácticamente imposible que tome una bebida helada incluso en verano, pero en mi caso, esto se da más por un tema de desagrado que por salud o por necesariamente conocer las propiedades medicinales del agua caliente.

La veneración a los ancestros y el respecto a los padres y a los mayores es un rasgo que la mayoría de las familias de origen chino mantienen. Asimismo, la memoria de los ancestros es recordada mediante ofrendas de fruta, vino y carnes ante tabletas de madera con los nombres de los difuntos (Dañino 2013: 120). En mi familia se han mantenido rezagos de estas prácticas utilizándose solo la colocación de fruta ante las tumbas de algunos ancestros. En cuanto al respeto por los mayores, me he podido percatar qué hasta hace algún tiempo, inconscientemente no he logrado contradecir a mis padres en decisiones importantes de mi vida como en la elección de mi carrera. La opinión de mis padres es transcendental, y aunque a veces quiera negarlo, con su reprobación no avanzaría ni un solo proyecto.

Actualmente, redacto mi tesis sobre las adopciones de apellidos de los inmigrantes chinos para obtener el título de abogada en la Facultad de Derecho y Ciencia Política de la Universidad Nacional Mayor de San Marcos. Asimismo, tengo como proyecto la formación de una institución tusán en Cañete, donde los descendientes de los inmigrantes chinos asen- 
tados en Cańete puedan compartir sus experiencias y rendir homenaje a los primeros chinos que llegaron a Cañete, asimismo de ser una institución encargada de la difusión de la cultura china y tusán en la provincia.

Por otro lado, tengo interés por viajar a China, sobre todo por conocer Guangdong y tratar en lo posible de reconstruir el pasado familiar, y aprender el idioma.

Pero la meta más importante para mí es reconstruir la historia de todos esos inmigrantes chinos y realizar un registro único de inmigrantes chinos donde todos los tusanes que como yo tuvieron o tienen inquietudes por indagar en su pasado puedan acceder fácilmente a una información a la que tienen derecho.

Finalmente, adjunto un pequeño relato que escribí sobre mi bisabuelo en Cañete con datos reales y algunos ficticios que no desvirtúan necesariamente su esencia.

\section{Un Cańete multicolor}

Les cuento la historia de aquel chino llegado desde Cantón a la hacienda Arona, que con su trabajo y el de sus compatriotas aportó al desarrollo de esta noble zona.

El chino Li era trabajador de tradición, con sus manos y mente, se hizo de un pequeño espacio en la hacienda cañetana. Llegó al Callao a fines del siglo XIX, y como resultado del destino terminó en tierras sureñas.

Diariamente regaba los campos con su sudor, al lado de sus paisanos. Los ancianos habían llegado hacía varias décadas, cuando la situación era mucho más agobiante. En el campo también conoció a muchos afros, y se percató que los paisanos y ellos no mantenían una buena relación, se miraban con algo de desdén y de vez en cuando tenían discusiones. Un paisano llamado Chau, asentado en La Quebrada, le contó que hace como diez años hubo un acontecimiento horrible: negros y andinos se rebelaron y en ese trajín persiguieron a los chinos y a muchos asesinaron. Varios paisanos pudieron protegerse y resistir dentro de Casa Blanca, luego de varios meses vinieron tropas que dispersaron a los rebelados, y los pobres paisanos pudieron verse liberados. Desde ese día

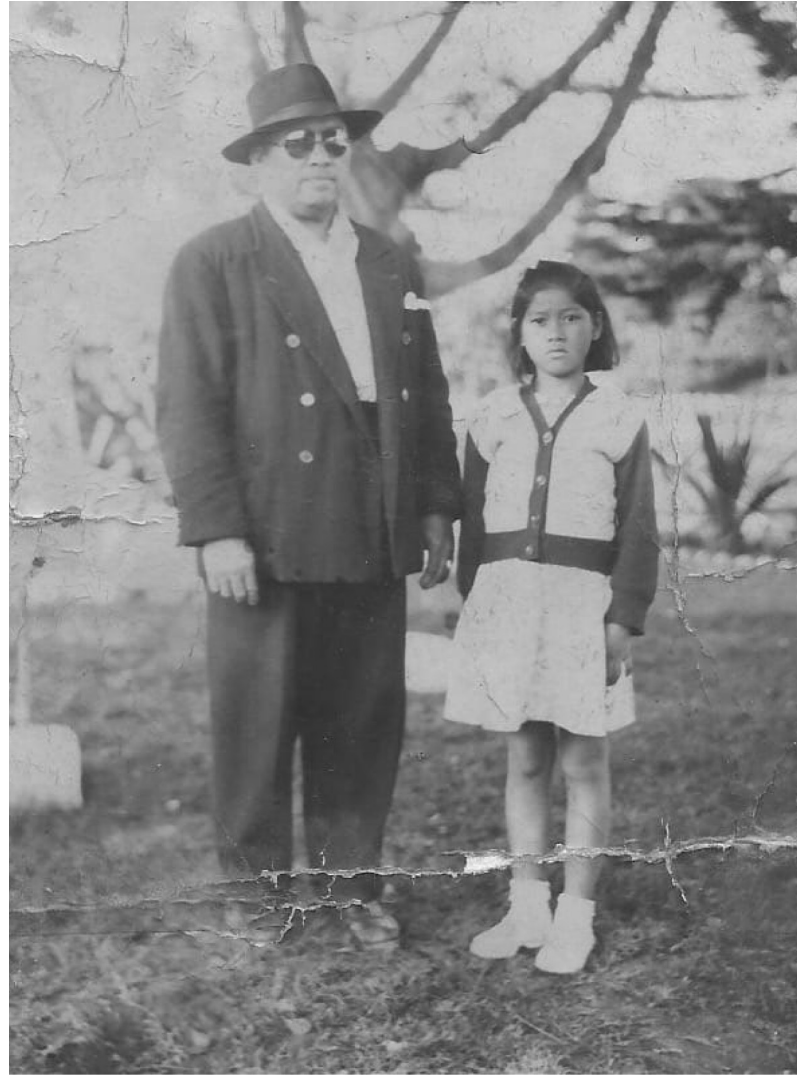

Mi tía Rosa Cortez junto a mi abuelo Manuel Cortez en Barranco, Lima, Perú.

una relación dura hay, por eso "debemos cuidarnos entre todos nosotros", le dijo Chau.

Las faenas en el campo eran fuertes, cuando caía el sol regresaba a su vivienda y descansaba. Un día, mientras intentaba dormir, escuchó unos golpes de tambores, parecía el sonido del tai ku, aquel tambor chino que retumbaba en cada danza de león. Un poco dubitativo salió de su vivienda, vio a un grupo de negros bailando al sonido de unas cajas con un agujero en el centro. Temeroso se acercó, uno de los danzantes le dijo: "ven, chinito, baila con nosotros". Li se sorprendió, aunque no entendía bien, el ademán que hizo el negro le confirmó que era una invitación a compartir con ellos. Pasó casi toda la noche ahí, el sonido lo consolaba y paradójicamente lo acercaba un poco a su añorada China. Pensó que los temores no debían invadirlo, los negros eran gentiles y hasta comida rara pero muy sabrosa le habían invitado.

En las siguientes semanas, Li tuvo más contacto con los paisanos de la colonia, se reunían en una casa de la calle Comercio en Pueblo Viejo. Tang le presen- 
tó a dos paisanos, gestores de esa organización, Lay y Lam, aunque fuera del círculo chino eran conocidos como José Colina y Pedro Torres, respectivamente. Li preguntó: ¿por qué usan esos nombres? Son nombres para esta tierra, es necesario usarlos, si no nadie nos entiende, no pueden pronunciar nuestros verdaderos nombres menos escribirlos.

-Lay, ¡cómo elegiste ese nombre?

-No lo elegí, es de un amigo de San Vicente, él me ayudó desde que llegué y fue mi padrino de bautismo.

- Y Ud. Lan?

-Mi caso no es tan agradable ni noble. Augusto Torres era un caporal, un desgraciado, nos golpeaba todo el día, todos los días. Por encargo del patrón, nos llevó a la iglesia para bautizarnos y nos dio su apellido.

Pasó un mes. El patrón buscó al grupo de los chinos recién llegados, incluido $\mathrm{Li}$, los llevó fuera de la hacienda, caminaron cerca de media hora, Li pudo observar desde lejos a dos maderos entrecruzados, y sin atajos desperdiciados, en la iglesia, delante del patrón, lo despojaron de su apellido y su instrucción. El patrón airado le dijo: "No entiendo tu lenguaje raro, desde ahora, castizo será tu nombre", "Dejarás de ser infiel, vivirás como la gente, respetando a nuestra madre santa, a favor de tu pobre alma”.

Li no entendía nada, hasta recordar la conversación que tuvo antes, le rociaron agua en la cabeza, el cura recitó palabras más extrañas que el español. Desde ahora tenía que recordar un nuevo nombre "José Dionisio Cortez", "ese es mi nombre peruano..."

Pasaba el tiempo, Li caminaba por los inmensos campos y de vez en cuando iba al Pueblo Viejo, en todos lados podía observar a un paisano. Muchos, por su inmenso trabajo, habían ascendido hasta los escaños más alturados. Li quería avanzar como ellos, fue bastante hábil, el encargado de la contabilidad de la British Sugar Company, notó su talento y le dio trabajo como su ayudante en sus oficinas ubicadas en Santa Bárbara, muy cerca al mar.

Allí conoció a muchos japoneses, tenían poco tiempo de haber llegado. Procedían de distintas prefecturas como Fukuoka, Kumamoto, Okinawa, o Shizuoka; comían un arroz jugoso llamado yakimeshi, al té lo llamaban ocha, tenían una sopa con mucho sabor, ramen le decían, y unas frituras exqui- sitas que tenían el nombre de tempura. Hasta habían construido un colegio para sus nińos. A pesar de las diferencias, ambos orientales compartían la misma reverencia por los ancestros y la afición por el trabajo.

El tiempo caminaba... Li vio a lo lejos una silueta... ¡Era Aquilina! la hija de un paisano cantonés que había adoptado el nombre de José Perez, su padrino de bautismo fue el Dr. Manuel Perez, vecino de Cañete. En esa mañana con el alba destellante, los campos de las inmensas haciendas se veían más verdes aún, todo era mejor. Ella era una jovencita, hermosa está de más decir, mestiza de afro y oriental. Se enamoraron y pronto tuvieron a su primera hija, Luisa. Desde entonces Li trabajó también para dar honor a su familia.

Un día más en Cañete, se realizó una fiesta en San Luis, al toque del cajón se reunió el afro, andino, chino y japonés, todos gozando en torno a un solo sentimiento. $Y$ así pues, se glorificó nuestro Cañete. Resultados somos de ellos, resultados de simbiosis de trabajo y amor. El trabajo los unió, en la tierra se conectaron y por obra del mismo cielo en seguida se mezclaron ¡No fue fácil! La vida dura fue, al principio la riña existió, mas luego fugó... y solo el amor creció en él. Las culturas unidas forjaron ahora a nuestro Cañete... Un Cañete multicolor que amamos hasta sin razón”

\section{Bibliografía}

Carrasco Atachao, Rebeca (2009). Proceso de inserción de inmigrantes chinos al Perú (1849-1930). El caso de San Luis de Cañete. Tesis para optar el título profesional de licenciada en antropología. Universidad Nacional Federico Villarreal.

Cipriano C. Zegarra, Félix (1872). La condición juridica de los estranjeros en el Perú. Chile: Imprenta de la Libertas.

DañIno, Guillermo (2013). Enciclopedia de la cultura china. China: Ediciones en lenguas extranjeras.

Rodríguez Pastor, Humberto (2000). Herederos del dragón. Historia de la comunidad china en el Perú. Lima: Fondo Editorial del Congreso del Perú.

Villanueva Salvatierra, Susan H. (2014). Del registro del matrimonio religioso al registro del matrimonio civil en el Perú. Nombres Revista Académica del RENIEC. 1, 1, 183-225. 